\title{
The Determinants of the Implementation of ERP according to Management Control System and the Global Performance of the Firm: Case of Tunisia
}

\section{Affes $\mathrm{H}^{*}$}

Department of Management Sciences, Sfax University, Tunisia

\begin{abstract}
Our present scientific perspective aims to be contingent. It will study the impact of the ERP on the main objective of management control system (MCS) which is the global performance improvement of the firm. This impact will depend on two main variables which are the strategy and the organizational structure. Dealing with the usefulness of ERP for successful companies, this paper firstly aims to identify the determinants of implementing an ERP "Enterprise Resource Planning systems" according to 29 management control responsible, and secondly, to evaluate the effect of this integrated information technology (IT) called ERP on the overall performance of companies which are organized by the processes. These latter are basically flattened, listed companies and ISO 9011 certification holder.

Moreover, the implementation of an ERP is a business project. It will involve an overhaul of an information system, including the overhaul of management processes within the organization. The greatness and the complexity of this project request a specific theoretical framework and an "empirical practice" looking for designing an adequate model while estimating the impact of the ERP setting-up on the whole company performance according to the controllers.
\end{abstract}

Keywords: ERP; Organizational performance; Tunisia

\section{Introduction}

Looking for the improvement of the main management control system (MCS) objective, Anderson's model stressed the importance of the commercial and risk issues that depends on humane behavior and organizational structure. The unifying model of Kwon et al. [1] has insisted that environmental factors for improving MCS are the adoption of a multimodal information system which considers environmental factors. (Managerial, human, technological and economic factors). In the present research will strive for highlighting the importance of the appropriate recent information technological (IT) system such as the enterprise resource system (ERP). This integrated system requiring the availability of an organizational structure by process, was very useful for General Motors Company's for piloting its global performance. It has been proved that ERP insures the activity based management and the activity based costing system $(\mathrm{ABC} / \mathrm{ABM})$. Nowadays, both of these two management accounting methods appear to be very important for the success of (MCS). Gosselin [2] justified, in the contingent prospect the role played by the strategy and the structure in the adoption of such accounting management innovation as the $\mathrm{ABC} / \mathrm{ABM}$ in a cross functional organizational structure.

These last years, the wave of the integrated software packages broke out on the function of management within large companies HueiHuang et al. [3]. These authors place software packages integrated into the heart of the tensions which are subject of cross functions management. Their main hypothesis is that the integrated software package intervenes as a mediator variable intended to manage the contradictory tension between the development of autonomy necessary for the flexibility, by more decentralized organizations, and the strengthening of the control relaying on the integrated information control system, its circuits and its processing procedure.

Kaplan et al. [4] proposed an integrated balanced score card tool with four strategic perspectives (Financial perspective, Customer Perspective, Business Processes Perspective, Learning and Growth Perspective with their - metrics and description) to manage and pilot the global performance of the firm relaying on the strategy deployment success. Capelo et al. [5] proves that the efficiency and the effectiveness of balanced score card and consequently the global performance of the firm depends on its computerizing and data processing endeavor.

Nowadays, Software packages ERP, translation of "Enterprise Resource Planning", has known a success mattering in particular in organizations (private or public) of any size and activity sector. The choice of implementing the ERP involves a replacement of the functional systems, a simplification and standardization of the organizational and management information systems, the improvement of the interactions and the communication with suppliers, customers and business partners, the acquisition of a strategic advantage and the reinforcement of the link between the whole activities [6]. This ERP breaks with the designing of an organization based on the functional specialization. Then, this organization should be cross functional, unbundled and flat $[7,8]$.

The main issue of our article rests on three shutters of search namely: Which organizational frame can handle the setting-up of the ERP? What are the key success factors which favor the functioning of the ERP? What is the nature of the link which can exist between the setting-up of the ERP and the whole objective of (MCS) which is the global performance of the company?

\section{Theoretical Background Definition of a System of ERP}

The expression of management package integrated (PGI) in

*Corresponding author: Affes $\mathrm{H}$, Department of Management Sciences, Sfax University, Tunisia, Tel: 658638639; E-mail: managementresearch6@gmail.com

Received June 02, 2016; Accepted July 15, 2016; Published July 21, 2016

Citation: Affes H (2016) The Determinants of the Implementation of ERP according to Management Control System and the Global Performance of the Firm: Case of Tunisia. J Glob Econ 4: 201. doi: 10.4172/2375-4389.1000201

Copyright: (c) 2016 Affes H. This is an open-access article distributed under the terms of the Creative Commons Attribution License, which permits unrestricted use, distribution, and reproduction in any medium, provided the original author and source are credited. 
summary is the French equivalent of the English term enterprise resource planning or ERP. The definition given by the 'CXP Information in February, 1994' groups all the constituent parameters of an ERP.

To be integrated, a management package owes emanate from a unique designer which guarantees to the user the uniqueness of information which is assured by the availability of the entire structure of the database from all of the modules. All the modules should be well audited to guarantee of a total traceability of the management operations and of all the information system of the company. The concept ERP (enterprise resource planning) indicates a software package understanding diverse modules which use a unique reference table that is a unique database and which assures the organizational coherence between the functions of the organization and the levels of management. In this concern Pérotin perceives the ERP as integrated software of management, grouping a set of customizable and modular IT applications, which aim at federating and at optimizing the processes of management of the company by proposing a unique and coherent reference table and resting on standard management rules. Usually, at the beginning of its adoption, ERP turns out to be a costly and embarrassing tool for employees because it requires a great parametrage and alignment effort with the procedures and with the status quo in matters of organization. Therefore it generates resistances to change. However once properly managed, it will lead to the success of the decision-making process which will be expressed in term of time saving, cutting cost and more adding value for the different stakeholders [9].

In the fifteen last years, the ERP also integrated upstream and downstream organizational processes (Customer relationship management, Supply chain management) as well as the processes of business intelligence (BI) and of knowledge management (KM). This has eased the management control system functions dealing with earning and performance valuation procedures called activity based management $(\mathrm{ABM})$ and activity based costing $(\mathrm{ABC})$. The whole processes and the value chain representing the company would become more valuable and strategically beneficial. Time saving and the value creation for stakeholders would be ensured. This objective fits that one of the well-known Kaplan and Norton's who had proposed a strong strategic managerial with its four orientations' perspectives striving for leveraging the whole performance of the organization [4]. The financial perspective, the customer, the processes and the human resource development perspective. In our research paper we will bring financial and commercial perspectives back to economic one. These three perspectives will lead us to an effective corporate strategy fulfillment.

Nevertheless the managers should manage the resistance to change relying on teamwork action plans and unconditional commitment.

Besides, the definition proposed by Willis et al. [10] turns out the most complete, "The ERP is an integrated system which allows the company to standardize its information system to connect and automate its basic processes. It supplies to the employees the necessary information to manage and control the essential activities of the company along the supply chain, along the supply in the production/ exploitation until the sale and in the delivery to the end customer. The employees enter only once the information, which are then put at the disposal of all the systems of the company".

\section{Lequeux [11], summarizes the characteristics of ERP as follows:}

- The effective management of several domains of the company by integrated modules or software packages susceptible to assure integration as well as a collaboration of the processes.
- The existence of a unique reference table of data; the reference table is defined as being all the references of the data as well as necessary indications to find the data themselves on a database.

- The standardization of the human-machine interfaces.

- The existence of tools of development or personalization of application complements.

\section{Advantages of an ERP}

The ERP systems represent the challenge of unifying and centralizing all the sub management modules in one unique and solid system. This will engage a common language and a common database which facilitate process of management. At this level, the ERP turns out to be advantageous at different level, such as:

- Integrating the activities of the organization by developing a great majority of the transactions.

- Facilitating the communication and the inter-organizational collaboration [12].

- Reaching the real time data $[13,14]$.

- Reducing the asymmetry of information. [15], But as any project, organizational, strategic and technical problems can arise in the organization.

\section{Determinants of the setting-up of the ERP systems}

Many factors and determiners can push towards the setting-up of the systems ERP in particular:

- The structural dimension, made a reference to the organization and to the functioning of the competence center constituted by the members of the project team ERP. A competence center brings a real added value on projects the life cycle of which is long and which will be brought to evolve strongly in time. The implementation of a competence center has to come along with the definition of a contract of services and with performance indicators.

- The strategic dimension makes a reference to the importance of the target organizational vision [16].

Within the framework of a project of setting-up of an ERP, the definition of an organizational target vision consists in drawing clearly the main lines of the future organization and the management that the actors of the project have to borrow to reach it. The dimension process business made a reference to the reengineering of business processes. It is necessary to decide on a change of the processes as the prerequisites of the setting-up of the ERP. The implementation of ERP comes along with a standardization of the internal processes to the company. The cultural dimension leaves the idea which the main reason of the failure of the projects ERP lies in the fact that we pay little attention on the culture of organizations and on its very important effects on the processes of planning, the setting-up and putting on of the project. In a culture of management of change, to make a success of the implementation of the ERP, two elements are considered essential:

- Training, to assure the skills and the capacity of the people to use effectively the ERP system and to guarantee its best functioning.

- The implication of the users in the setting-up of the ERP which constitutes a key factor of success for the change management. 
The implication of the head office is considered one of the FCS of the implementation of the ERP (the project of setting-up of an ERP has to obtain the approval and the support of the head office. It is important that the project becomes the project of all the company, from the top management until the operational. The marketing dimension makes a reference for the use of the ERP. The TAM (Technology Acceptance Model) postulated that the use of ICTS (Information and Communication Technologies) is determined by a behavioral intention to use a system, and the latter is jointly determined by the attitude of the people and the received utility [17].

The dimension success of SI made reference to the satisfaction of the users to assure the success of implementation of the system ERP. The evaluation of the success of SI is a domain of interest for the search in management of the information system $[18,19]$. The model proposed by DeLone et al. [18] demonstrates that the success of IF is estimated by: the quality of the system, the quality of the information, the use, the satisfaction of the users, the individual impact and the organizational impact. This model was enriched latterly, in particular by the addition of a new dimension: the implication of the users and the engineering of the change.

\section{Problems connected to the setting-up of an ERP}

Rao [20] asserted that a significant percentage of setting-up of the ERP corresponds to a partial or total failure. From an analysis of the literature focused on the causes of failures [21,22], we can notice that the latter are caused by technical and organizational factors.

- The technical factors of the problems can appear: those relative to a coexistence of two systems, a new and other former information system In fact, the analysts of the setting-up of the ERP advised the companies to avoid bringing modifications to software packages.

- The organizational factors, in particular dilemma caused by a lack of skills so internal as external, technical that organizational, and those relative to the adaptation and the organizational adequacy.

\section{The Impact of the Setting-Up of an ERP on the Global Performance of Companies}

The global performance of a SME (Small and Medium-Sized Enterprise) can contain: an economic performance, an organizational performance and a human performance in the sense of Florescu, on 2007 [23]. Concerning the economic performance, it is the capacity of the entity to reach these fixed goals, it often confronts financial indicators. We also speak about an economic performance measured by the competitive position of the company and its competitive capacities.

The use of an ERP favors the "total quality" and even the "competitive position" of the company. The organizational performance is defined as being "the way the company is organized to reach its goals and the way it succeeds in reaching them".

In this context Kalika [24] released or cleared some criteria of evaluation of the organizational performance namely: the quality of the circulation of information, the relations between the services (departments), the coordination, the cooperation, the degree of control, the communication, the decentralization, the flexibility and the integration.

The human performance analyzes to leave the results obtained by the employees and the employees on jobs, a service or a whole entity.
By these potentialities, an ERP constitutes a vector of the improvement of the human performance, both in the individual plan and the team one. The investment in an ERP tool is not in itself the guarantor of the performance of the company. The ERP, as any information system, must be considered as an asset of the company and not a uniquely designed support of its activity.

\section{The Impact of the ERP on the economic performance}

The ERP allows automating the transactions what leads to an acceleration of the processes and the increase in the volumes of the operations. Besides, thanks to the integration of the diverse applications, the ERP harmonizes the various processes of the company. All this engenders according to Shang and Seddon a cost cutting, a reduction of the time of the operational cycle and the improvement of the productivity and the quality. Besides, the installation of the ERP reduces the maintenance costs of the Information system and increases the capacity of the firm to spread new features of the information system [9]. It could support the firm's corporate strategy and the objective achievement speed up in a crossfunctional manner.

Consequently, we can conclude that the ERP favors the optimization of the resources and the costs, the deadlines control and the productivity enhancement. Where-of, the customers will benefit from a reduction of the deadlines which are imposed on them, will benefit from the price reduction as well as the improvement of the quality of the supplied services. Sales are thus going to increase and the company will become more competitive. Indeed, according to Shang and Seddon, thanks to the ERP, the company can acquire competitive advantages, and it is true by offering products to moderate costs and by improving the relation of the company with its customers and with the various stakeholders. This orientation fits that one of the balanced score card with its four integrated performance perspectives.

By referring to the criteria of economic measurement of performance, we can conclude of what preceded that the ERP allows improving the economic performance.

\section{The impact of the ERP on the organizational performance}

The ERP supplies to the organizational actors a common language and a common database. This allows to improve the quality of the communicated information and thus to reduce the conflicts and to favor the coordination between the various services. Indeed, the integration which exists between the various modules of the ERP facilitates the cooperation within the organization.

So, the ERP opens new perspectives in organizational material by facilitating the passage of forms of organizations based on a functional specialization, a hierarchical coordination and a sequential process of decision to more multi-purpose organizations, valuing the horizontal coordination and processes of decision more decentralized [25].

Besides, the setting-up of the ERP facilitates the activities of control in the company. Indeed, by deleting the tasks of seized again manual workers of the information, the ERP allows to eliminate typing errors. Consequently, most of the activities of control are more made up stream, that is from the creation of source data (new customers, new articles). Besides, the existence of a unique database shared by all the functional modules of the ERP facilitates the control and the validation of the accounting transactions stemming from operational processes. To sum up, the ERP allows:

\section{- To improve the quality of the communicated information.}


- To favor the coordination.

- To decentralize the decisions.

- To facilitate the control.

By referring to the criteria of organizational measurement of performance, we can deduce that the ERP allows improving the organizational performance.

\section{The impact of ERP on the human performance}

Thanks to its centralized database, to the real-time information which it supplies and in its capacity to analyze the data, the ERP helps the leaders in the process of decision-making and in the planning, it also allows them afterward to improve the direction of the resources and to improve the performance of the various operational decisions.

Besides, the ERP also contributes to the improvement of the knowledge of the staff. Indeed, the introduction of the ERP supposes that the end users of this new technology have to acquire new skills to treat it better. They also have to reach certain level of confidence and efficiency during the use of the ERP allowing them to improve their productivity [26]. It should be noted that the staff could show a certain resistance to the setting-up of the ERP. This resistance to change could give some explanations by the concern expressed by the staff and who is due to the risk of cut of employment led by the automation of tasks. Besides, the employee is often used to a way to work who is of an important specialization, and the fact of working in a group in the presence of the ERP could constitute a problem for them. Besides, this resistance is also a consequence of the lack of information on behalf of the staff about the project [27].

This is why training turns out to be necessary during the introduction of the ERP. In fact, added to its contribution to the scientific plan, this training should also inform the staff of the various advantages of the ERP from which he could benefit during the fulfillment of his task.

To conclude, the ERP helps the decision makers to become more effective leaders and to improve the skills and the productivity of the employee. By referring to the criteria of human measurement of performance, we can end that the ERP allows improving the human performance.

\section{Methodology of Search and Analysis of the Results}

From a multi-criterion analysis by the determiners of the settingup ERP, we tried :

- To know which companies have similar organizational performances.

- To characterize the groups of the most organizational companies.

- To highlight the hierarchical links between companies and group of companies.

The determiners of the setting-up ERP are established of five dimensions: strategic, marketing, cultural, success of SI and structural.

\section{Hypothesis}

Hypothesis of the effect of the variable "Satisfaction of the users" on the report of chance of realization of a level of organizational performance.

Hypothesis H1: The adoption of ERP has a positive and significant impact on the performance of the company.
Hypothesis H2: Using indicators of performance only has a positive and significant impact on the performance of the company.

Hypothesis H3: The joint adoption of ERP systems has a positive and significant impact on the financial performance of the company. Our purpose of the classification is to produce the arborescence which is highlighted by hierarchical links between companies from the dimensions of the setting-up ERP. By means of a vague typology, we describe the data, as that which allows to realize a distribution is not optimal, but interesting in one hand, and to identify the companies which belong to several classes and to understand better the reasons of these multiple memberships in the other hand. We shall present first of all the followed methodology. We also shall examine the results obtained by means of a vague typology and a hierarchical ascending classification (AHP).

We shall study models of 29 companies of the accounting year 2015 according to their determiners of the setting-up ERP in an accounting management manner: vision targets of MCS responsible, their perception of ERP, standards and values, satisfaction of the users, and their competencies. The problem is to know to which extent could companies be grouped and when this grouping should be stopped regarding these criteria.

To answer has this question; we shall proceed to a hierarchical ascending classification (criterion of ward) from the reduced centered data. To fulfill this classification, it is necessary to define a measure of resemblance between companies in term of their management control practices.

To understand the functioning of the algorithm, we define a level of cut which is translated by a variability infraclasses' small and variability collate big, and the quality of a partition is measured by the loss of total inertia. Loss of internal inertia/loss of total inertia.

If the loss of the inertia during the passage of $p$ lists in $p-1$ class is very important, it means here that the grouping is natural. We use an algorithm of functioning by means of the Euclidian distance and the criterion of guard after the standardization of the data because the units of measure are different. We tried first of all to know if there is a hierarchical link between the previous determiners of the ERP settingup according to the new management control responsible's vision. This relation is verified for five dimensions (correlation of row of Spearman from 0.9 to 0.4 significant of $5 \%$ and $1 \%$ ). It is interesting for the continuation, because a company which is badly classified risks of leading a not natural arborescence.

We established economic indicators power plant and of dispersal for every dimension of the setting-up ERP to visualize the dispersal of the data. Mustaches go of the first quartile Q 0.25 at least and the third quartile Q 0.75 at most. It has a length which does not have to exceed the inter-quartile. The lower or superior extreme points are isolated on the graph by a circle.

In sum the loss of inertia finds the sum of the value determiners of ERP setting-up which are centered and reduced.

A hierarchical ascending classification of the data which is built by means of the Euclidian distance (dynamic distance and average distance between classes give the same results) a typology in three classes (Figure 1) and the diagram of the level indications (Figure 2) showed us that the loss of inertia during the passage of four classes in three classes is very important. The division in three groups gives us: Loss of internal inertia/loss of total inertia $0.228 / 5=45.6 \%$ 
Citation: Affes H (2016) The Determinants of the Implementation of ERP according to Management Control System and the Global Performance of the Firm: Case of Tunisia. J Glob Econ 4: 201. doi: 10.4172/2375-4389.1000201
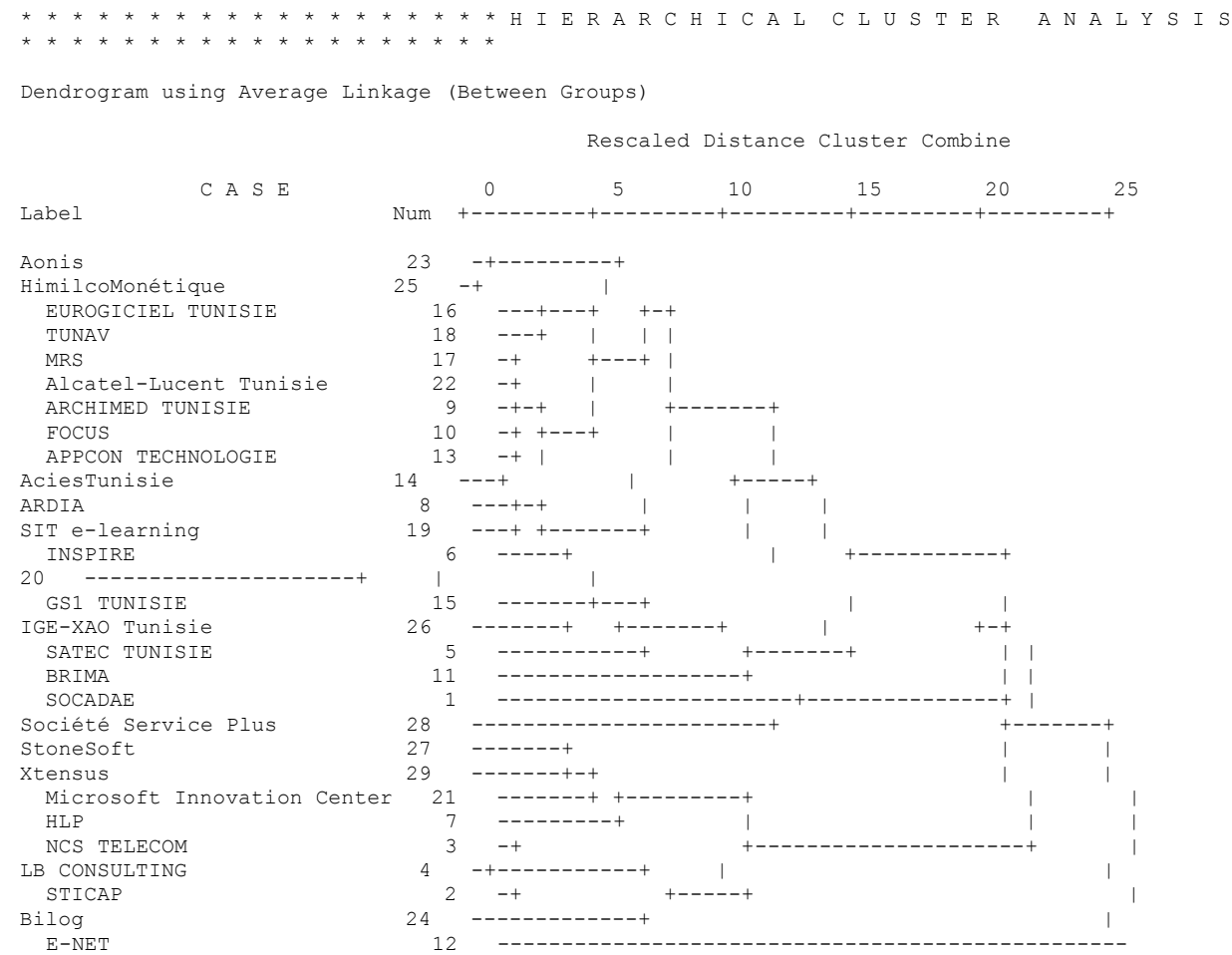

Figure 1: Hierarchical Tree and inter-enterprise arborescence.

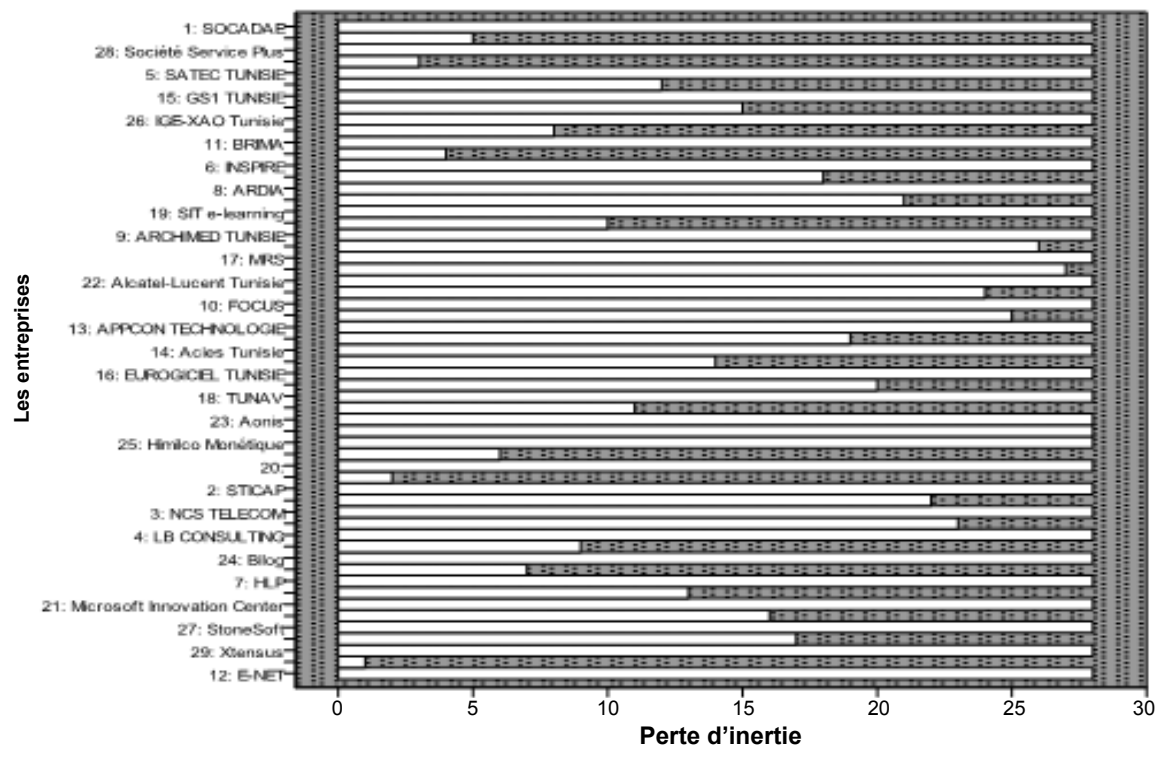

Figure 2: Evolution of the inertia for various distribution of the sample.

That means that when we separate companies in three groups, this separation gets back $45.6 \%$ of the training. We see that Aonis, Eurogiciel Tunisia, Inspire ...companies have similar and very close organizational performances and that they are the least successful. The group of companies GS1TUNISIE, IGE-XAOTUNISIE, and SATEC Tunisia is rather homogeneous. They are averagely economically successful. More in detail, the Microsoft Innovation Center and Xtensus companies are the most organizational and successful.
In the concern to estimate the link between the setting-up of the ERP and the organizational performance for 29 companies, we propose an analysis finer than the AHP. Of this fact we try to explain the degree of organizational performance by a model to give an answer by the structural of multinomial logit type. This report must be justified in our study by verifying the connection between three specific alternatives of the degree of organizational 
Citation: Affes H (2016) The Determinants of the Implementation of ERP according to Management Control System and the Global Performance of the Firm: Case of Tunisia. J Glob Econ 4: 201. doi: 10.4172/2375-4389.1000201

Page 6 of 7

performance, and by using the Hausman test (HM) and the test of Small Hasio (SH).

These two tests are generally based on the measure of the gap between the estimated parameters in the complete model and those of this model in which an alternative in summer eliminated. If the gap is statistically significant, the hypothesis IIG is then rejected.

Regarding our questioning about the chance calculation ratio, or the risk ratio explained by the odds ratio measuring the probability ratio which could inform us about the company performance, it becomes easy to make prediction. This previous prediction will be obtained by comparing it to a very low organizational performance degree. This also depends on the quality of the model. This latter has to be specified by a ratio of a chance which is lower than 1 to indicate that there is more chance that the organizational performance comes true. We note RR the ratio of chance:

$$
R R=\frac{\operatorname{Pr}\left[\frac{\text { performance org }=2}{x}\right]}{\operatorname{pr}\left[\frac{\text { performance org }=1}{x}\right]}
$$

The result of the analysis of link between every determiner of the setting-up of ERP and the organizational performance by the logit multinomiale model is exposed by the Table 1 below:

The results indicate a quality of acceptable adjustment in spite of relatively low R2. The line of Chi-square allows realizing the likelihood test, and indicates that the coefficients estimated on both of the following equations are simultaneously different from zero.

These two following estimation equations which describe the probability of the risk could take the following shape:

$\log \left[\frac{\operatorname{pr}(\text { performance org }=2)}{\text { pr }(\text { performance org }=1)}\right]=3.31^{*}$ target vision $+1.65^{*}$ Standard and value $+1.52^{\star}$ Competence center

\begin{tabular}{|c|c|}
\hline Déterminant of ERP & $\begin{array}{c}\text { Coefficient } \\
\text { (z-stat) }\end{array}$ \\
\hline $\begin{array}{c}\text { Low degree of Performance org==1 } \\
\text { target vision } \\
\text { Perception of ERP } \\
\text { Standard and value } \\
\text { Satisfaction of users } \\
\text { Competence center } \\
\text { Reorganization Process }\end{array}$ & ${ }^{* *}$ Reference alternative ${ }_{-}^{* *}$ \\
\hline $\begin{array}{c}\text { Low degree of Performance org==2 } \\
\text { target vision } \\
\text { Perception of ERP } \\
\text { Standard and value } \\
\text { Satisfaction of users } \\
\text { Competence center } \\
\text { Reorganization Process }\end{array}$ & $\begin{array}{l}3.31^{* *} \\
0.54^{* *} \\
1.65^{*} \\
0.012 \\
1.52^{*} \\
0.323\end{array}$ \\
\hline $\begin{array}{c}\text { Low degree of Performance org==3 } \\
\text { target vision } \\
\text { Perception of ERP } \\
\text { Standard and value } \\
\text { Satisfaction of users } \\
\text { Competence center } \\
\text { Reorganization Process }\end{array}$ & $\begin{array}{l}3.54^{* * *} \\
0.741^{*} \\
1.47^{*} \\
0.034 \\
1.482^{*} \\
0.895\end{array}$ \\
\hline $\begin{array}{l}\text { Number of observation } \\
\text { L- likelihood } \\
\text { LR Chi-deux } \\
\text { P-Value } \\
\text { R }^{2}\end{array}$ & $\begin{array}{c}31 \\
-88.321414 \\
33.214 \\
0.0021 \\
0.247\end{array}$ \\
\hline
\end{tabular}

Table 1: Ratio of chance stemming from the model logit multinomiale. $\log \left[\frac{\operatorname{pr}(\text { performance org }=3)}{\operatorname{pr}(\text { performance org }=1)}\right]=3.54^{\star}$ target vision $+1.47^{\star}$ Standard and value $+1.48^{\star}$ Competence center

Our results of estimation based on the coefficient of the ratio of risk show that we cannot accept the hypothesis of the effect of the variable "satisfaction of the users" on the report of chance of realization on a level of organizational performance compared with the not successful companies (RR1).

On the contrary:

${ }^{\star}$ An increase of a unit of target vision undergoes an increase of 3.31 the logarithm of the report of the probability of realization of a degree of average and low performance and 3.54 the logarithm of the report of the probability of realization of a high and low degree of performance.

*The improvement of the standard and the value of the company engender a ratio of chance of the organizational average performance of 1.65 , and a ratio of chance of the high organizational performance of 1.47 .

*The demonstration of a competence center for companies reveals 1.52 of the chance of the organizational performance with average probability and 1.48 of the chance of the organizational performance with high probability.

\section{Conclusion}

The ERP systems become more and more valued with SME (Small and Medium-Sized Enterprise) which evolve in a more and more complex and changeable context. Yet, Tunisians SME are confronted with a diversity of problems namely: saturated markets, greater competitiveness, more demanding and less faithful customers, etc. The problem comes because the company is generally organized according to a functional model characterized by the multiplication of sub-information systems. To deal with this problem of dispersal of the information and by the obligations of competitiveness, the company tries to modify its vertical organization by function to pass to a horizontal organization by process customer-oriented.

This new model supposes the integration of the main processes of the company and the implementation of a coherent information system guaranteeing the uniqueness of the information and the access to this one from all the functions of the company. Software packages ERP (Undertaken Resources Schedule) come to support such organizational and strategic orientations.

In fact, if many Tunisian companies are attracted by the ERP, it is because the latter is supposed to bring gains of productivity and efficiency, in particular by its capacity to return the more integrated (joined) organization. This integration concerns as well the (automatisable) processes of the company as the information handled by the software. Indeed, the integration is placed among the main reasons which urge companies to equip themselves with an ERP.

\section{References}

1. Kwon TH, Zmud RW (1987) Unifying the Fragmented Models of Information Systems Implementation. John Wiley, New York.

2. Gosselin M (1997) The Effect of Strategy and Organizational Structure on the Adoption and Implementation of Activity-Based Costing. Accounting, Organizations and Society 22: 105-122.

3. Huei-Huang C, Shih-Chih C, Li-Hung T (2009) A Study of Successful ERP from the Organization Fit Perspective. Systemics, cybernetics and informatics 7 : 8-16. 
Citation: Affes H (2016) The Determinants of the Implementation of ERP according to Management Control System and the Global Performance of the Firm: Case of Tunisia. J Glob Econ 4: 201. doi: 10.4172/2375-4389.1000201

4. Kaplan RS, Norton DP (2002) Le tableau de bord prospectif.

5. Capelo C, Lopes A (2015) A Simulation-Based Approach for Teaching the Systems Perspective of Strategic Performance Management. International Journal of Accounting Education 24: 1-26.

6. Mabert V, Soni A, Venkatamaran M (2000) Enterprise Resource Planning Survey of U.S. Manufacturing Firms. Production and Inventory Management Journal.

7. Davenport TH, Short JE (1990) The New Industrial Engineering: Information Technology and Business Process Redesign.

8. El Amrani R (2003) Vision organisationnelle cible comme facteur de réussite d'un projet ERP: le cas SAP chez l'entreprise Consto, 8 ème colloque de l'AIM, Grenoble.

9. Gattiker T, Goodhue D (2000) Understanding the Plant Level Costs and Benefits of ERP: Will the Ugly Duckling Always Turn into a Swan? Hawaii International Conference on Systems Sciences.

10. Willis T, Willis-Brown, Mcmillan A (2003) Stratégies de maîtrise des coûts lors de l'implantation de systèmes ERP.

11. Lequeux JL (1999) Manager avec les ERP, progiciels de gestion intégrés et interne. Les Editions d'Organisations, Paris.

12. Hardy C, Phillips N (1999) No Joking Matter: Discursive Struggle in the Canadian Refugee System. Organization Studies 20: 1-24.

13. Leary DE (2000) Enterprise Resource Planning Systems (Systems, Life Cycle Electronic Commerce, and Risk). Cambridge University Press, UK.

14. Booth P, Matolcsy Z, Wieder B (2000) Integrated Information Systems (ERPsystems) and Accounting Practice. The Australian Experience.

15. Markus ML, Tanis C (2000) The Enterprise System Experience \pm from Adoption to Success.
16. El Amrani R (2003) Vision Organisationnelle Cible Comme Facteur de Réussite d'un Projet ERP: le cas SAP chez l'entreprise Consto.

17. Legris P, Ingham J, Collerette P (2003) Why do People use Information Technology? A Critical Review of the Technology Acceptance Model. Information and Management 40: 191-204.

18. DeLone WH, McLean ER (1992) Information Systems Success: The Quest for the Dependent Variable. Information Systems Research 3: 60-95.

19. McGill TJ, Hobbs VH, Klobas JE (2000) Testing the DeLone and McLean Model of IS Success in the User Developed Application Domain.

20. Rao SS (2000) Enterprise Resource Planning: Business Needs and Technologies. Industrial Management \& Data System 100: 81-88.

21. Davenport T, Klahr P (1998) Managing Customer Support Knowledge. Harvard Business Review, California.

22. Themistocleous M, Irani Z, O'Keefe R (2001) ERP and Application Integration: Exploratory Survey. Business Process Management Journal 7: 195-204.

23. Florescu $V$ (2007) TIC et performance de l'entreprise: un modèle généra d'analyse, Revue Repères Economique et informatiques.

24. Kalika M (1988) Structures d'entreprises-Réalités, Déterminants, Performance, Economica, Coll.

25. Brousseau E, Rallet A (1999) Technologies de l'information, organisation et performances économiques. Rapport au Commissariat Général du Plan, Paris.

26. Fourati $F(2006)$ Veille stratégique : l'évaluation de l'utilisation des agents intelligents.

27. Berghman, Jos (2003) Connecting Welfare Diversity within the European Social Model. 